\title{
EFFECTS OF FLUTAMIDE ON SEX MATURATION AND BEHAVIOR OF OFFSPRING BORN TO FEMALE RATS TREATED DURING LATE PREGNANCY
}

\author{
Kazunori GOTO ${ }^{1}$, Keiji KOIZUMI ${ }^{1}$, Hitoshi TAKAORI ${ }^{1}$, Yoshinobu FUJII ${ }^{1}$, \\ Yuko FURUYAMA ${ }^{1}$, Osamu SAIKA ${ }^{1}$, Hiroetsu SUZUKI ${ }^{2}$, \\ Kenichi SAITO ${ }^{2}$ and Katsushi SUZUKI ${ }^{2}$ \\ ${ }^{1}$ Department of Toxicology Research, Odawara Research Center Nippon Soda Co., Ltd., \\ 345 Takada, Odawara-shi, Kanagawa 250-0280, Japan \\ ${ }^{2}$ Nippon Veterinary and Animal Science University, \\ 1-7-1 Kyonan-cho, Musashino-shi, Tokyo 180-8602, Japan
}

(Received March 5, 2004; Accepted August 24, 2004)

\begin{abstract}
Flutamide, when administered subcutaneously to female rats at doses of 3, 10, or $30 \mathrm{mg} /$ $\mathrm{kg} /$ day during late pregnancy (gestational days 16-21), significantly and dose-dependently decreased anogenital distance (AGD) of the male offspring in each dose group compared to controls. Significant delays in preputial separation were found in males at a dose of $30 \mathrm{mg} / \mathrm{kg}$, but body weight gain was not inhibited. Cryptorchidism and absence of the prostate gland and seminal vesicles were found in males at doses $\geq 10$ $\mathrm{mg} / \mathrm{kg}$, and testicular hypoplasia at a dose of $30 \mathrm{mg} / \mathrm{kg}$. Hypospadias was noted in all dose groups and vaginal pouches at doses of $\geq 10 \mathrm{mg} / \mathrm{kg}$. The effects on the accessory reproductive organs were severe, although the effects on the testes themselves were mild. However, those effects appeared to become more pronounced with growth, as evaluated on Days 30 and 42 and Weeks 16 to 18 . Most of these affected animals displayed cryptorchidism. Male offspring exposed to flutamide in utero showed impairments of sexual behavior as adults in a dose-related manner. Number and frequency of mounts with intromissions was markedly decreased in all treated groups as compared to controls. At $10 \mathrm{mg} / \mathrm{kg}$, no mounting with ejaculation was observed, and at a dose of $30 \mathrm{mg} / \mathrm{kg}$, no mounting with intromission or ejaculation was observed. These changes in sexual behavior were closely associated with abnormalities of the external genitalia. Animals with hypospadias did not display mounts with ejaculation. However, F1 males that copulated at a dose of $3 \mathrm{mg} / \mathrm{kg}$ had a normal reproductive function. Histological examination of the reproductive organs revealed degeneration of the seminiferous tubules, hypospermatogenesis, and hypoplasia and inflammation of the seminal vesicles and prostate. Serum levels of FSH, LH, and testosterone in these animals were comparable between control and all dose groups. Therefore, the male reproductive dysfunction seen in the present study could not be attributed to abnormal sex hormone levels during maturation, but to possible demasculinization of the brain and progressively delayed dysmorphorogy of the male genitalia caused by fetal exposure to flutamide.
\end{abstract}

KEY WORDS: Flutamide, Anti-androgen, Sex maturation, Sexual behavior, Late pregnancy, Rats

\section{INTRODUCTION}

Flutamide, an androgen receptor antagonist, and finasteride, a $5 \alpha$ reductase inhibitor, were antiandrogens used in human clinical practice. Flutamide is commonly used for treatment of prostate cancer (Balk,
2002), and is also widely used in research on endocrine disrupters. Suppressive effects of flutamide on sexual maturation and behavior have been reported in rats when administered during the perinatal period (Clemens et al., 1978; Brand and Slob, 1991; Zimmerberg and Farley, 1993; Lund et al., 2000) or to 
offspring immediately after birth (Gladue and Clemens, 1978, 1980; Clemens et al., 1978; Brand and Slob, 1991; Vega Matuszczyk and Larsson, 1995; Miyata et al., 2002). Other chemicals such as antiandrogen drugs finasteride (Clark et al., 1990, 1993; Wise et al., 1991; Imperato-McGinley et al., 1992) and cyproterone acetate (Clemens et al., 1978), and the estrogen-like chemical bisphenol A (Sato et al., 2001; Cagen et al., 1999) have been reported to cause various changes in morphology of the external genitalia and sexual maturation of the offspring born to mothers treated with these chemicals during pregnancy.

Administration of these substances from late pregnancy to postnatal day (PND) 3, the so-called "critical period", can exert a profound effect on sexual maturation and behavior of male rats (Gray et al., 1994). Administration of antiandrogens during this critical period has been associated with findings in male newborns of decreased anogenital distance (AGD), retained nipples, hypoplasia and malformations of the external genitalia, hypoplasia and absence of the internal genitalia, cryptorchidism, blind vaginal pouches, and hypospermatogenesis (Mylchreest et al., 1998; Gray et al., 1994; You et al., 1998; Ostby et al., 1999). In addition, sexual behavior in males is under the control of sex hormones, and exposure to antiandrogen and estrogen substances is known to exert feminized effects on sexual behavior in males (Sodersten $e t$ al., 1975; Gladue and Clemens, 1982; Vagell and McGinnis, 1998). In a study on castrated rats, Gladue and Clemens (1980) found that flutamide clearly inhibits testosterone-induced sexual behavior such as mounting, intromission and ejaculation, suggesting that testosterone binding to androgen receptors plays an important role in male sexual behavior expression. Several investigators have also reported that exposure to antiandrogens such as flutamide during pregnancy is associated with feminization of sexual maturation and behavior in male offspring (Clemens et al., 1978; Gladue and Clemens, 1978; Brand and Slob, 1991; Vega Matuszczyk and Larsson, 1995). Miyata et al. (2002), using rats treated with flutamide from late pregnancy to postnatal Day 3, reported abnormalities in AGD, testicular descent and external genitalia, and decreased weights of accessory reproductive organs in F1 male offspring. Effects on sex hormone levels (increased LH, FSH and T) were also noted, and sperm studies identified decreased sperm counts and abnormal morphology.

Few studies have investigated the degree to which abnormalities of the external genitalia and hypoplasia of the accessory reproductive organs due to antiandrogens affect sexual behavior or reproductive function in males. The present study therefore administered the androgen receptor antagonist flutamide to female rats during late pregnancy to evaluate the effects of in utero exposure on sexual maturity, sexual behavior, and reproductive function in male offspring.

\section{MATERIALS AND METHODS}

\section{Experimental animals and drug administration}

Crj:CD (SD) IGS SPF rats (9-week-old) were purchased (Charles River Japan, Atsugi, Japan), quarantined and acclimatized for one week, then used for study (age at start of mating, 10 to 11 week-old). Healthy males and females at proestrus, as identified by vaginal smears, were housed together overnight to mate at 1:1 basis. Next morning, when sperm-positive smear or vaginal plugs were found, the day was designated as gestation day (GD) 0 . Female rats with confirmed pregnancy were randomized based on their body weight to treatment groups at the start of the study. Animals were housed individually in stainless steel cages in an animal room with a controlled environment: temperature, $18-24{ }^{\circ} \mathrm{C}$; humidity, $40-80 \%$; and a 12-hr light/dark cycle (light, 0700-1900). During the study, animals were fed CA-1 laboratory animal chow (CLEA Japan, Tokyo, Japan) and tap water $a d$ libitum.

Flutamide, obtained from Sigma Chemical Co. Ltd (St. Louis, Miss), was dissolved in demethylsulfoxide (DMSO). DMSO concentration was adjusted to $5 \%$ by adding olive oil to prepare test drug solutions at specified concentrations. Test drug solution was administered at doses of $0,3,10$, and $30 \mathrm{mg} / \mathrm{kg} / \mathrm{day}$, at a volume of $0.5 \mathrm{~mL} / \mathrm{kg}$, once daily, by subcutaneous injection around the neck. Periods of treatment were GD 0-5 during pre-implantation, GD 6-17 during fetal organogenesis, and GD 16-21 during late pregnancy. A control group was also established with administration of olive oil and DMSO in the same manner. In studies during pre-implantation and fetal organogenesis, each group contained 10 animals. In the main study during late pregnancy, each group was comprised of 12 animals.

Animals treated during the periods of preimplantation (GD 0 to 5) and organogenesis (GD 6 to 17) were sacrificed on GD 20, and fetuses were removed to determine sex and the presence or absence of external abnormalities. Animals treated during late pregnancy were allowed to deliver spontaneously. On 
Sex maturation and behavior of offspring exposed to flutamide.

postnatal Day 7, newborn offspring were culled to totally 12 per litter as the same number per sex as possible.

\section{Clinical observations and clinical pathology}

Pregnant dams were examined daily for clinical signs of toxicity and death. Body weight and food consumption were measured on specified days throughout pregnancy and lactation. In dams sacrificed on GD 20, fetuses were removed, and AGD was measured using calipers. Offspring born by spontaneous delivery were examined for external abnormalities, then AGD was measured in a similar manner on the day of birth. Footpads of each offspring were injected with India ink for individual identification.

Offspring viability was examined immediately after delivery and during nursing, and body weight was measured during nursing and after weaning. Developmental parameters, including eyelid opening and eruption of the incisors, were evaluated in all viable pups from postnatal Day 8 until maturity. For sexual maturation, preputial separation for males and vaginal opening for females were recorded. The day on which the penis came out when the surrounding area of genital tubercle was gently pressed was defined as onset of preputial separation. Among F1 pups reaching 16 to 18 weeks-old, one male and female from each litter were selected and placed in metabolic cages. Cumulative urine samples were collected for $16 \mathrm{hr}$ for urinalysis (urine volume, color, specific gravity, $\mathrm{pH}$, glucose, protein, ketone bodies, bilirubin, urobilinogen, and occult blood). The same animals were anesthetized with ether, and blood was collected from the posterior vena cava. Samples were centrifuged at $3000 \mathrm{rpm}$ for 10 min, and serum was used for measurement of biochemical parameters (Aspartate aminotransferase, Alanine aminotransferase, Alkaline phosphatase, $\gamma$-Glutamyl transpeptidase, Cholinesterase, Triglyiceride, Total Cholesterol, Glucose, Blood Urea Nitrogen, Creatinine, Total Bilirubin, Total Protein, Albumin, Ca, Inorganic $\mathrm{P}, \mathrm{Na}, \mathrm{K}$, and $\mathrm{Cl}$ ) using an $\mathrm{H}-7070$ auto-analyzer (Hitachi Co., Hitachi, Japan).

\section{Serum hormone levels}

On PND 21 (at weaning), one female pup from each litter was selected, and blood was collected from the posterior vena cava. Samples were centrifuged, and serum was used for measurement of estradiol (E2) concentration. On PND 30, blood samples were collected from one female and male in each litter for measurement of serum levels of E2 for females, $\mathrm{T}(\mathrm{T})$ for males, and free T (f-T) for males. On PND 42, blood samples were collected from one male in each litter for measurement of serum levels of T, f-T, LH, and FSH. Assays were performed using radioimmunoassay (RIA) kits (FSH and LH: Daiichi Kagaku Yakuhin, Tokyo, Japan; T, f-T and E2: Diagnostics Products Corporation, Los Angeles, CA, USA).

\section{Male reproductive function and sexual behavior 1. Testing of male reproductive function}

For testing of reproductive function in males, untreated female rats (10-week-old) of the same strain were purchased separately for mating. These untreated, mature females were cohabitated with males from each study group for at least one week. If mating could not be confirmed (i.e., no sperm present in vaginal smear), males were cohabitated with another female for one week again. In females with confirmed mating, necropsy was performed on GD 21 to examine the number of implantation sites, number of live/dead fetuses, corpora lutea count, and presence or absence of external abnormalities of live fetuses.

\section{Testing of male sexual behavior}

To produce persistent estrus females, ovariectomized female rats were purchased from the Institute for Animal Reproduction (Niihari, Ibaraki, Japan). Then, the females were subcutaneously injected with 2 $\mu \mathrm{g} /$ day of $\beta$-estradiol for 3 days and followed by subcutaneous injection of $500 \mu \mathrm{g}$ progesterone by $3 \mathrm{hr}$ before the study. The estrus females, recognized as persistent estrus by observation of vaginal smear, were placed in cages with the test males, and an infrared camera was set up in a dark location, and then sexual behavior was videotaped for two hours without daynight reversion. Male sexual behaviors in the videotapes were later observed and recoded in accordance with the methods of Hokao et al. (1993), Hokao and Saito (1994), and the number of mounts (number of mounts without intromission), number of intromissions (number of mounts with intromission), and number of ejaculations (number of mounts with ejaculation) were counted. In addition, time until start of each type of sexual behavior (latency) and lordosis behavior in males were recorded.

\section{Necropsy, measurement of organ weights, and his- tological examination}

On PND 30 and 42 and postnatal week (PNW) 16-18, one male and female from each litter were sacrificed for necropsy. The brain, thyroid gland, liver, 
kidneys, adrenal glands, testes/ovaries, epididymides, and prostate glands were weighed, and each organ was preserved in $10 \%$ neutral buffered formaldehyde. The reproductive organs, including testes, ovaries, epididymides and prostate, were histologically examined.

\section{Statistical analysis}

For parametric continuous variables (e.g., body weight, organ weights), Bartlett's test (Bartlett, 1937) was used to analyze differences in variance among groups. If no significant difference ( $\mathrm{p} \geq 0.05)$ was noted, Dunnett's test (Dunnett, 1955) was used for intergroup comparisons. If a significant difference $(\mathrm{p}<0.05)$ was present, Steel's test (Steel, 1959) was used. Mean weights for pups before weaning were analyzed in litter unit. Due to wide variations in serum hormone levels, the Wilcoxon rank sum test was used to compare differences with the control group. If necessary, the Jonckheere test (1- side) was used for trend analysis. For statistical analysis, computer software of the SAS ${ }^{\circledR}$ system v8.2 (SAS Institute Japan, Tokyo), JMP ${ }^{\circledR}$ v4.05J (SAS Institute Japan) and Yuckms ${ }^{\circledR}$ v2 (Yuckmus Corp., Tokyo) were employed.

\section{RESULTS}

\section{Effects on dams}

No adverse effects on clinical signs or body weight changes of dams treated with flutamide were observed when treated during either early (GD 0-5) or middle (GD 6-17) pregnancy period. A slight but statistically significant reduction in food consumption was observed on GD 9-12 at dose of $30 \mathrm{mg} / \mathrm{kg}$ when the dams were treated during late pregnancy (GD 16$21)$. No changes for dams were noted with organ weights, number of corpora lutea, implantation sites or fetal mortality at necropsy for the dams treated on either treatment period. For dams treated during late pregnancy and allowed to deliver, no significant differences were noted for body weight changes and any reproductive parameters, such as pregnancy rate, pregnancy length or total litter loss between control and flutamide treated groups.

\section{Effects on fetuses exposed in utero during early or middle pregnancy}

Fetal sex ratio and fetal body weight at GD 20 in the treatment groups in either treatment period were comparable to those in the control group. Incidences of external anomalies were within normal ranges. A significant reduction in AGD for males was observed at doses $\geq 3 \mathrm{mg} / \mathrm{kg}$ in the fetuses exposed during GD 6-17, but not GD 0-5 (Fig. 2).

\section{Post-natal effect on growth of F1 pups exposed dur- ing late pregnancy}

The survival rate or weaning index of pups at dose of $30 \mathrm{mg} / \mathrm{kg}$ tended to be slightly reduced as compared to controls, but no significant differences were apparent (Table 1). Birth weights of pups were similar among control and treatment groups, but significantly lower body weight $(\mathrm{p}<0.05)$ was observed at the dose of $30 \mathrm{mg} / \mathrm{kg}$ for males at weaning, while females displayed no changes (Fig. 1). Gains in body weight after weaning generally displayed a normal increasing pattern in all groups. Urinalysis and blood chemistry examinations for pups at 16- to 18 -week-old revealed no abnormal changes in any dose groups (no data shown). AGD of pups at birth was significantly decreased in all dose groups as compared to controls $(\mathrm{p}<0.05)$, and clear dose-related responses were evident (Fig. 2). Time to preputial separation for males at dose of $30 \mathrm{mg} / \mathrm{kg}$ was significantly larger than those for controls $(p<0.01)$. Sex maturation of females was unaffected by treatment (Table 2). Hypospadias was observed in males of all treatment groups in a dosedependent manner and all males displayed hypospadias at doses of 10 and $30 \mathrm{mg} / \mathrm{kg}$, and half of males at a dose of $3 \mathrm{mg} / \mathrm{kg}$. Vaginal pouch was also observed in all treatment groups with significantly increased prevalence and in a dose-dependent manner. Such malformation of external genitalia was noticed with more severity in higher doses. Cryptorchidism was markedly and significantly increased at doses of 10 and $30 \mathrm{mg} / \mathrm{kg}$ $(\mathrm{p}<0.01)$, and slightly increased at $3 \mathrm{mg} / \mathrm{kg}$. No cases of cryptorchidism were observed in the control group. No trend toward laterality (right or left) was noted in affected animals and cases of bilateral cryptorchidism were rare (Table 3 ).

\section{Male sexual behavior and reproductive function}

No significant differences were observed in number of mounts, probably due in large part to marked individual differences, but frequency and number of mounts was clearly decreased in a dose-dependent manner $(\mathrm{p}<0.05)$. Frequency of intromissions for 10 $\mathrm{mg} / \mathrm{kg}$ was significantly lower as compared to the control and no intromissions in $30 \mathrm{mg} / \mathrm{kg}$, and while no significant difference in $3 \mathrm{mg} / \mathrm{kg}$ was observed, a lower tendency was noted. Furthermore, ejaculation was not seen at doses of 10 and $30 \mathrm{mg} / \mathrm{kg}$ (Fig. 3 and 4). Starting time (latency) of each behavior exhibited no dose- 
Sex maturation and behavior of offspring exposed to flutamide.

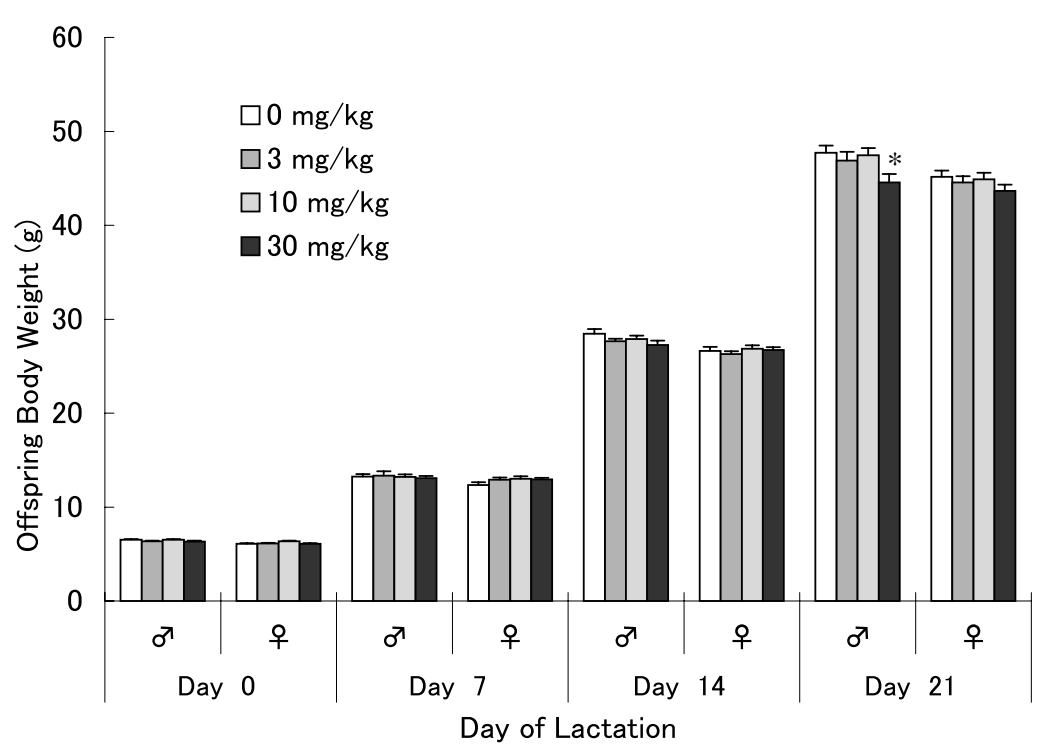

Fig. 1. Effect on body weight changes in the male and female pups during lactation period when administered with flutamide to rats during late pregnancy. (Mean \pm S.E.) $* \mathrm{p}<0.05$ vs control, by Dunnett's test.

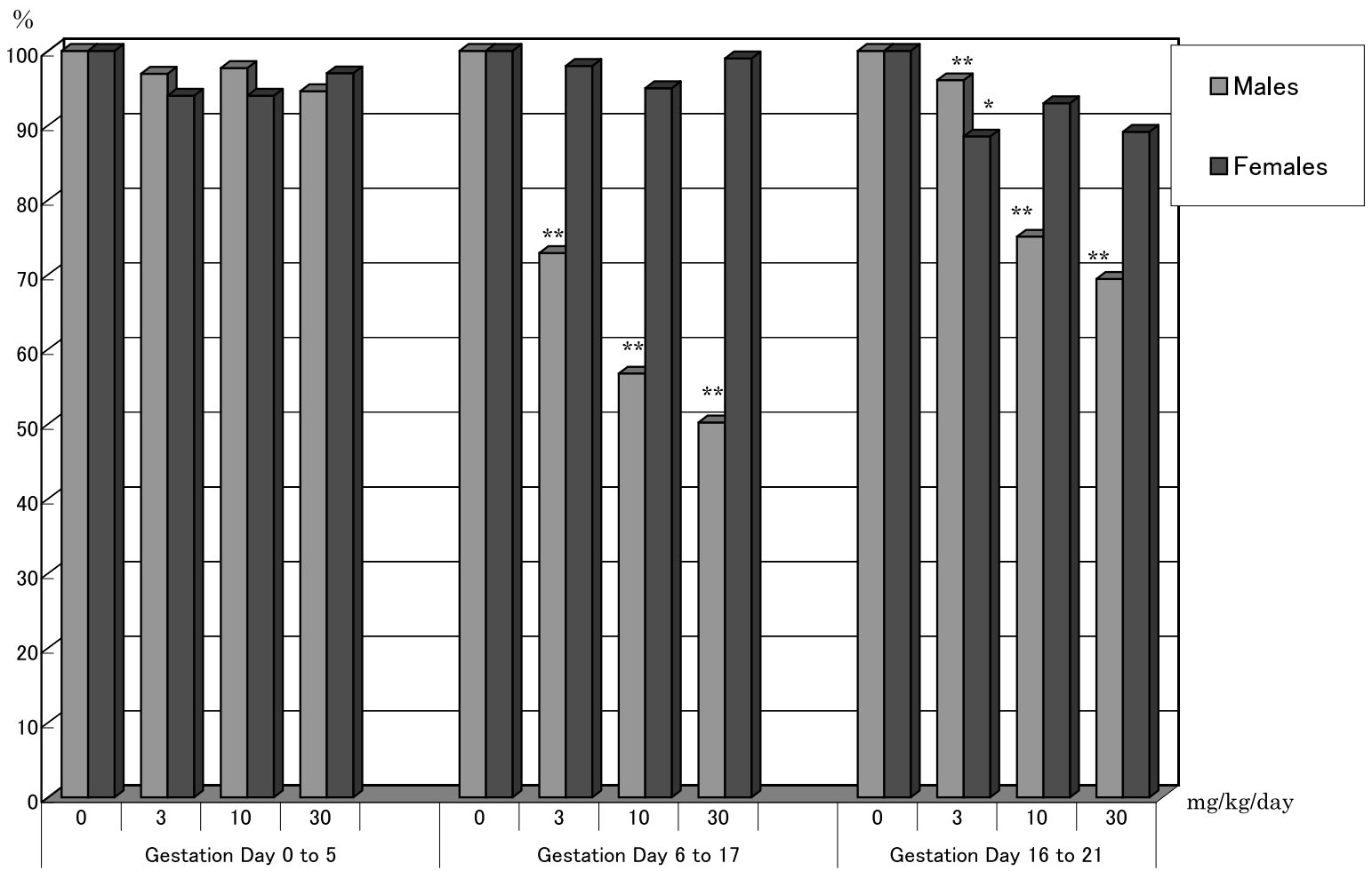

Fig. 2. Effect on AGD in fetuses or newborn pups exposed in utero to flutamide.

Fetuses exposed from GD (Gestation Day) 0 to 5 or from GD 6 to 17 were measured on GD 21 and newborn pups exposed from GD16 to 21 were at birth.

${ }^{*} \mathrm{p}<0.05,{ }^{*} \mathrm{p}<0.01$ vs each concurrent control, Dunnett's test.

Bars of the graph indicate ratios $(\%)$ to each control. 


\section{K. GOTO et al.}

Table 1. Reproductive and nursing performances of F0 females administered with flutamide from GD 16 to 21 .

\begin{tabular}{|c|c|c|c|c|}
\hline Dose $(\mathrm{mg} / \mathrm{kg})$ & 0 & 3 & 10 & 30 \\
\hline Females : Paired & (12) & (12) & (12) & (12) \\
\hline Pregnant & $9(75.0)^{\dagger}$ & $10(83.3)$ & $12(100)$ & $11(91.7)$ \\
\hline Delivering & 9 & 10 & 12 & 11 \\
\hline Duration of gestation (days): & $22.11 \pm 0.33 \neq$ & $22.10 \pm 0.57$ & $22.25 \pm 0.45$ & $22.09 \pm 0.30$ \\
\hline \multicolumn{5}{|l|}{ Pups survival indices (Mean\%) } \\
\hline $\begin{array}{l}\text { Livebirth index } \\
\text { (Number born alive/number born) }\end{array}$ & 97.8 & 100.0 & 99.3 & 97.0 \\
\hline $\begin{array}{l}\text { Viability index } \\
\text { (Number alive Day } 7 \text { precull / number liveborn) }\end{array}$ & 82.7 & 95.5 & 88.0 & 80.8 \\
\hline $\begin{array}{l}\text { Weaning index } \\
\text { (Number alive at weaning/ number alive at Day } 7 \text { postcull) }\end{array}$ & 96.5 & 100.0 & 100.0 & 89.2 \\
\hline \multicolumn{5}{|l|}{ Pups disposition (Total) } \\
\hline Culled day 7 & 16 & 17 & 23 & 6 \\
\hline Died & 30 & 7 & 20 & 37 \\
\hline Pups surviving at 21 days (Total) & 86 & 120 & 114 & 97 \\
\hline \multicolumn{5}{|l|}{ Pups dying, killed, missing and/or cannibalized (Total) } \\
\hline Days 0 - 7 & 43 & 24 & 43 & 40 \\
\hline Days 8-21 & 3 & 0 & 0 & 3 \\
\hline \multicolumn{5}{|l|}{ Entire litter died, missing, and /or cannibalized (Total) } \\
\hline Days $0-7$ & 1 & 0 & 1 & 1 \\
\hline Days 8-21 & 0 & 0 & 0 & 1 \\
\hline
\end{tabular}

$\dagger$ Percent

¥ Mean \pm S.D.

Table 2. Effects on physical and sexual developments in F1 pups exposed in utero to flutamide during GD 16 to 21.

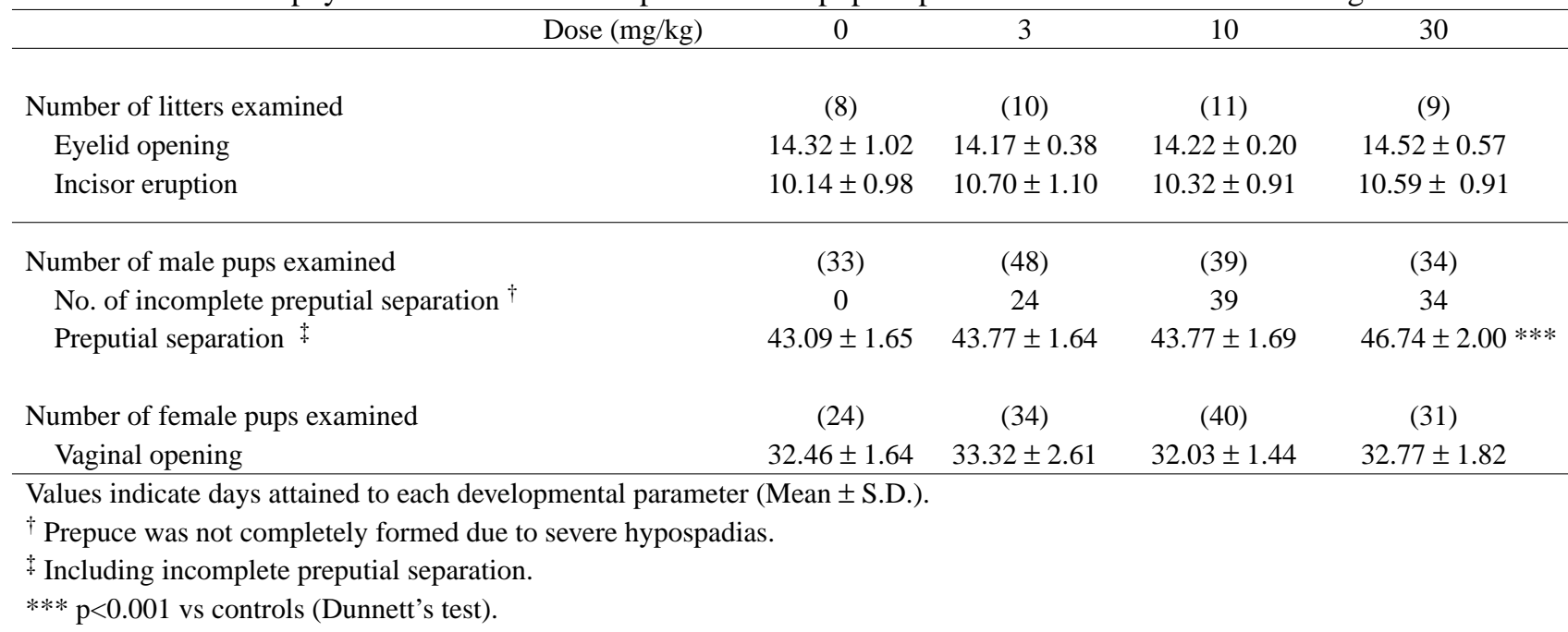


Sex maturation and behavior of offspring exposed to flutamide.

dependency and no correlation to number and frequency of each behavior. Abnormal male sexual behaviors such as lordosis were not seen in any groups.

Male reproductive functions for $\mathrm{F} 1$ generation were analyzed, and sperm were identified in the vaginal plug of all control animals, and copulation and fer- tility rates were both $100 \%$ (Table 4). Conversely, at 3 $\mathrm{mg} / \mathrm{kg}$, sperm were seen in the vaginal plug in 5 of the 10 animals (50\%). Of these, 4 animals became pregnant $(40 \%)$. Fertility rate was therefore $80 \%$. At 10 and $30 \mathrm{mg} / \mathrm{kg}$, copulation and fertility rates were $0 \%$. At 3 $\mathrm{mg} / \mathrm{kg}$, all five animals that copulated were shown to

Table 3. Effects on external genitalia of F1 male pups exposed in utero to flutamide from GD 16 to 21 .

\begin{tabular}{|c|c|c|c|c|c|c|}
\hline & & Dose $(\mathrm{mg} / \mathrm{kg})$ & 0 & 3 & 10 & 30 \\
\hline No. of animals examined & & & $(45)$ & $(61)$ & $(57)$ & $(46)$ \\
\hline Hypospadias & & & 0 & $29(47.5) * * *$ & $57(100) * * *$ & $46(100) * * *$ \\
\hline Vaginal pouch & & & 0 & $2(3.3)$ & $41(71.9) * * *$ & $41(89.1) * * *$ \\
\hline Undescended testicle & total & & 0 & $5(8.2)$ & $23(40.4) * * *$ & $22(47.8) * * *$ \\
\hline \multirow[t]{3}{*}{ (Cryptorchidism) } & right & & 0 & $1(1.6)$ & $11(19.3) * *$ & $11(23.9) * * *$ \\
\hline & left & & 0 & $3(4.9)$ & $11(19.3) * *$ & $10(21.7) * *$ \\
\hline & bilateral & & 0 & $1(1.6)$ & $1(1.8)$ & $1(2.2)$ \\
\hline
\end{tabular}

()$: \%, * *: \mathrm{p}<0.01, * * *: \mathrm{p}<0.001$ (Fisher's exact test)

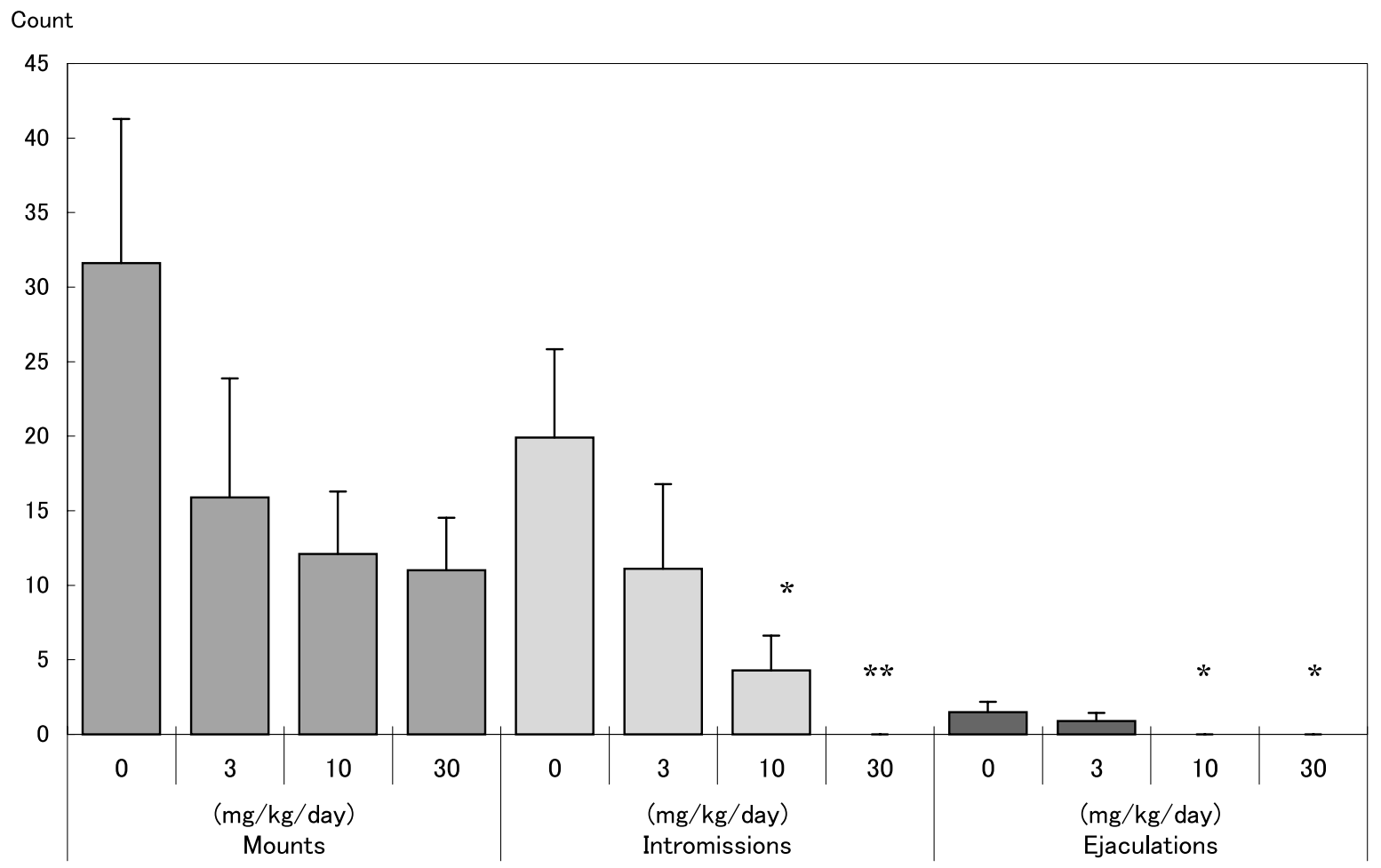

Fig. 3. Effect on sexual behavior for F1 males when paired with an intact estrous female.

Data are mean \pm S.E. values for each behavior counted for $120 \mathrm{~min}$.

There are no statistically significant differences in dose groups for mounting behavior as compared to control, but a decreased trend was statistically indicated by analysis with Jonckheere test $(\mathrm{p}<0.05)$.

${ }^{*} \mathrm{p}<0.05,{ }^{* *} \mathrm{p}<0.01$ by Wilcoxon's rank sum test. 


\section{K. GOTO et al.}

be capable of producing offspring. Compared to the controls, no significant differences in number of corpora lutea, implantation sites, early and late embryos, live fetuses or gender ratio were observed in pregnant animals mated with F1 treated males exposed to flutamide at $3 \mathrm{mg} / \mathrm{kg}$.

\section{Necropsy findings in F1 pups}

\section{Necropsy on PND 30}

Absence of the prostate gland was observed in 4 of 9 and 7 of 8 pups examined and absence of the sem- inal vesicles in 2 of 9 and 7 of 8 pups at doses of 10 and $30 \mathrm{mg} / \mathrm{kg}$, respectively. No abnormalities in either organ were observed at a dose of $3 \mathrm{mg} / \mathrm{kg}$ or in controls. For both abnormalities, incidence was significantly increased at the dose of $30 \mathrm{mg} / \mathrm{kg}$ as compared to controls. No female pups showed abnormal changes to internal genitalia.

\section{Necropsy on PND 42}

Absence of the prostate gland was observed in 4 of 11 and 8 of 8 pups examined, and absence of the
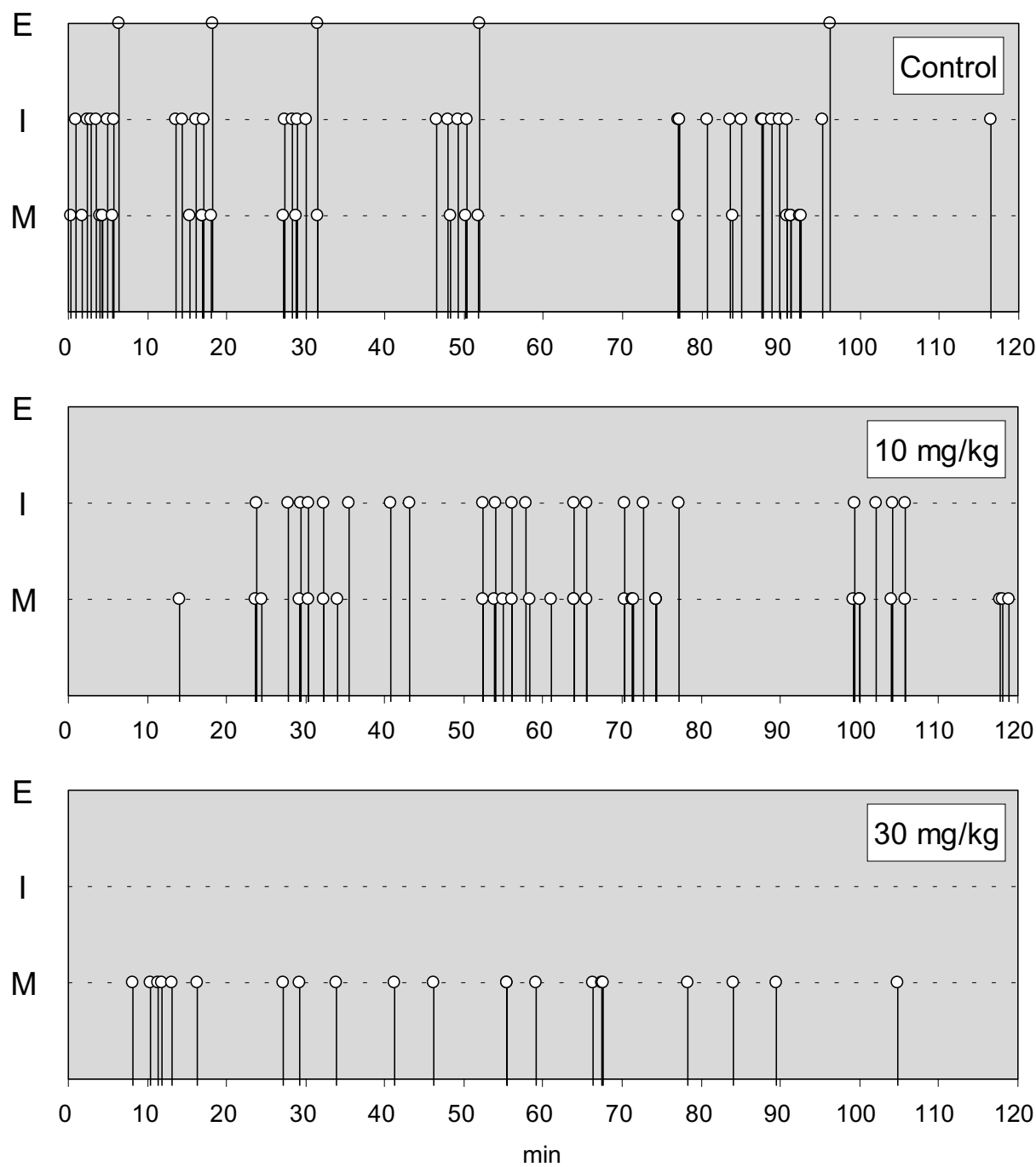

Fig. 4. Representative patterns of sexual behavior in F1 males. Control: normal pattern.

$10 \mathrm{mg} / \mathrm{kg}$ : moderately affected, no ejaculations.

$30 \mathrm{mg} / \mathrm{kg}$ : severely affected, no ejaculations and intromissions.

E: ejaculation, I: intromission, M: Mount. 
Sex maturation and behavior of offspring exposed to flutamide.

seminal vesicles in 3 of 11 and 3 of 8 pups at doses of 10 and $30 \mathrm{mg} / \mathrm{kg}$, respectively. Only incidence of absent prostate at the $30 \mathrm{mg} / \mathrm{kg}$ dose was significantly increased compared to controls ( 0 of 8 pups). In addition, a small number of males with atrophied testes and epididymides were observed at the dose of $30 \mathrm{mg} / \mathrm{kg}$.

\section{Necropsy in PNW 16-18}

Reduced size of the testes was significantly more frequent at doses of 10 and $30 \mathrm{mg} / \mathrm{kg}$ as compared to controls, and a dose-related response was evident. Absence of the prostate gland was observed in all males examined at doses of 10 and $30 \mathrm{mg} / \mathrm{kg}$. Hypoplasia of the seminal vesicles and absence of the coagulating gland were observed in almost all males at doses of 10 and $30 \mathrm{mg} / \mathrm{kg}$. Only one male showed absence of the seminal vesicles at the dose of $30 \mathrm{mg} /$ $\mathrm{kg}$. No such abnormalities in these organs were identified at the dose of $3 \mathrm{mg} / \mathrm{kg}$ or in controls. No females examined displayed any abnormalities.

\section{Organ weights in F1 male pups}

On PND 30, weight of epididymides tended to be slightly light (no significant difference) at the dose of $30 \mathrm{mg} / \mathrm{kg}$, and the prostate showed marked hypoplasia at doses of 10 and $30 \mathrm{mg} / \mathrm{kg}$ (Table 5). Prostate weight at dose of $3 \mathrm{mg} / \mathrm{kg}$ was comparable to control value. On PND 42, prostate gland was markedly small in weight at the dose of $10 \mathrm{mg} / \mathrm{kg}$ and slightly smaller at $3 \mathrm{mg} / \mathrm{kg}$. The testes weight was significantly lower

Table 4. Fertility of F1 males exposed to flutamide in utero from GD 16 to 21.

\begin{tabular}{|c|c|c|c|c|c|}
\hline & Dose $(\mathrm{mg} / \mathrm{kg})$ & 0 & 3 & 10 & 30 \\
\hline No. of males examined & & (8) & (10) & (11) & (8) \\
\hline \multicolumn{6}{|l|}{ No. of females } \\
\hline Mated with the males & & 8 & $5 *$ & $0 * * *$ & $0 * * *$ \\
\hline Pregnant & & 8 & $4 *$ & $0 * * *$ & $0 * * *$ \\
\hline Mean corpora lutea & & $17.3 \pm 3.3$ & $16.0 \pm 5.0$ & - & - \\
\hline Mean implantations & & $13.9 \pm 4.2$ & $13.0 \pm 6.5$ & - & - \\
\hline Mean pre-implantation loss (\%) & & $20.0 \pm 22.7$ & $23.8 \pm 22.0$ & - & - \\
\hline Mean post-implantation loss (\%) & & $2.4 \pm 3.4$ & $8.2 \pm 11.8$ & - & - \\
\hline \multirow[t]{2}{*}{ No. of live fetuses } & & 108 & 50 & - & - \\
\hline & & $13.5 \pm 4.0$ & $12.5 \pm 7.0$ & - & - \\
\hline \multirow[t]{2}{*}{ Males } & & 56 & 25 & - & - \\
\hline & & $7.0 \pm 2.8$ & $6.3 \pm 3.0$ & - & - \\
\hline \multirow[t]{2}{*}{ Femals } & & 52 & 25 & - & - \\
\hline & & $6.5 \pm 2.1$ & $6.3 \pm 4.6$ & - & - \\
\hline
\end{tabular}

Mean \pm S.D.

- : No data $*: \mathrm{p}<0.05, * * *: \mathrm{p}<0.001$ (Fisher's exact test)

Table 5. Effects on sexual organs in the F1 pups exposed in utero to flutamide from GD 16 to 21.

\begin{tabular}{|c|c|c|c|c|c|}
\hline & Dose $(\mathrm{mg} / \mathrm{kg})$ & 0 & 3 & 10 & 30 \\
\hline \multicolumn{2}{|c|}{ Number of animals examined } & (8) & $(10)$ & (9) & (8) \\
\hline \multirow[t]{3}{*}{ PND 30} & Testes & $0.563 \pm 0.081$ & $0.645 \pm 0.12$ & $0.652 \pm 0.129$ & $0.562 \pm 0.161$ \\
\hline & Epididymes (g) & $0.094 \pm 0.015$ & $0.102 \pm 0.02$ & $0.104 \pm 0.017$ & $0.079 \pm 0.027$ \\
\hline & Prostate $\quad(\mathrm{g})$ & $0.059 \pm 0.010$ & $0.064 \pm 0.023$ & $0.034 \pm 0.017 *$ & - \\
\hline \multicolumn{2}{|c|}{ Number of animals examined } & (8) & (10) & (11) & (8) \\
\hline \multirow[t]{3}{*}{ PND 42} & Testes $\quad(\mathrm{g})$ & $1.463 \pm 0.273$ & $1.597 \pm 0.135$ & $1.467 \pm 0.209$ & $1.293 \pm 0.238 *$ \\
\hline & Epididymes (g) & $0.226 \pm 0.050$ & $0.243 \pm 0.035$ & $0.235 \pm 0.021$ & $0.214 \pm 0.047$ \\
\hline & Prostate & $0.141 \pm 0.029$ & $0.125 \pm 0.027$ & $0.078 \pm 0.047 * *$ & - \\
\hline \multicolumn{2}{|c|}{ Number of animals examined } & (6) & (9) & (6) & (7) \\
\hline \multirow[t]{2}{*}{ PNW 16-18 } & Testes & $3.403 \pm 0.144$ & $3.376 \pm 0.465$ & $2.747 \pm 0.617 *$ & $1.899 \pm 0.579 * *$ \\
\hline & Epididymes (g) & $1.414 \pm 0.086$ & $1.312 \pm 0.101$ & $1.161 \pm 0.203$ & $0.874 \pm 0.225 * *$ \\
\hline
\end{tabular}

Values are Mean \pm S.D. for group. PND: Postnatal day, PNW: Postnatal week.

$* \mathrm{p}<0.05, * * \mathrm{p}<0.01$ vs. controls (Dunnett's or Steel's test) $\quad-$ : Not detectable. 
only at a dose of $30 \mathrm{mg} / \mathrm{kg}$, but the reduced testis weight was prominent at 16 to 18 week-old $(p<0.01)$. The same was true at a dose of $10 \mathrm{mg} / \mathrm{kg}(\mathrm{p}<0.05)$. Testes weight in treated animals became much more severely affected over time. The epididymis in PNW 16 to 18 was also significantly small $(\mathrm{p}<0.01)$ in weight at the dose of $30 \mathrm{mg} / \mathrm{kg}$. No changes in the weight of those organs were noted at the dose of $3 \mathrm{mg} /$ $\mathrm{kg}$.

\section{Hormonal assay}

In F1 males, no significant differences between control and treatment groups were observed in total or f-T levels on either PND 30 or 42, due to wide interindividual variations in values. Although FSH and $\mathrm{LH}$ were measured concurrently on PND 42, no biologically meaningful patterns in relationships of gonadotropins and $\mathrm{T}$ levels were identified following flutamide treatment (Table 6). E2 levels for F1 female pups on PND 21 and 30 were within normal ranges in all groups.

\section{Histopathological examination}

On PND 30, no histological changes were evident in the testes in F1 males exposed to flutamide in utero, even at a dose of $30 \mathrm{mg} / \mathrm{kg}$. On PND 42 and PNW 16-18, however, degenerated lesions were observed in testes with 10 and $30 \mathrm{mg} / \mathrm{kg}$ (Table 7). Interstitial cell hyperplasia (sertoli cell-only syndrome; Photo 1) was also observed at these doses, but not clearly dose-related on PND 42. The histopathological alterations in the testes were less prominent in descended testes. At final necropsy (PNW 16-18), animals with seminiferous tubule degeneration displayed markedly reduced numbers of sperm in the epididymides (oligospermia) at doses of $10 \mathrm{mg} / \mathrm{kg}$ and higher. In addition, animals at $30 \mathrm{mg} / \mathrm{kg}$ showed evidence of inflammation. Histological examination of other internal genitalia identified inflammation of the atrophied prostate glands and seminal vesicles (Photo 2). Inflammation of the prostate was not observed at any other doses on PND 30 and 42. In histological examination of external genitalia, the urethra was observed in the center part of the glans penis in controls (Photo 3), but it was located at the ventral surface of the penis in the treated males at doses of 10 and $30 \mathrm{mg} / \mathrm{kg}$ (Photo 4). The surface of the dorsal side of the penis was bordered by epithelium, while the ventral side was covered with urethral epithelium in the affected males. The prepuce of the ventral side of the penis was hypoplastic in males having hypospadias and vaginal pouch $(*$ in Photo 4).

\section{DISCUSSION}

Flutamide at doses of 3,10 , and $30 \mathrm{mg} / \mathrm{kg} / \mathrm{day}$ by subcutaneous administration during pre-implantation (GD 0-5) or fetal organogenesis (GD 6-17) produced no toxic signs in dams. Necropsy of the dams at term showed no effects on number of implantation sites or fetal death rate. Examination of live fetuses exposed to flutamide during pre-implantation period revealed no

Table 6. Hormonal levels in F1 pups exposed in utero to flutamide from GD 16 to 21.

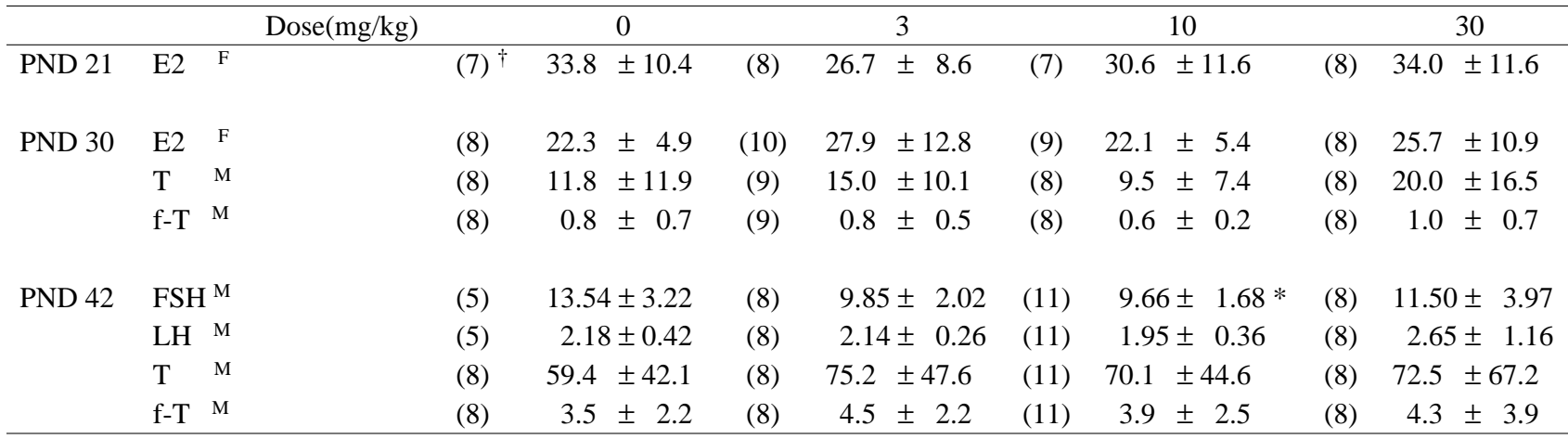

FSH: Folicular stimulating hormone (ng/ml), LH: Lutenizing hormone (ng/ml).

E2: Estradiol (pg/ml), T: total Testosterone ( $\mathrm{ng} / \mathrm{ml})$, f-T: free Testosterone (pg/ml).

Values indicate Mean \pm S.D.

${ }^{\dagger}$ Number of animals examined, ${ }^{\mathrm{M}}$ Measured for males, ${ }^{\mathrm{F}}$ Measured for females.

$* \mathrm{p}<0.05$ vs control (Wilcoxon rank sum test). 
Sex maturation and behavior of offspring exposed to flutamide.

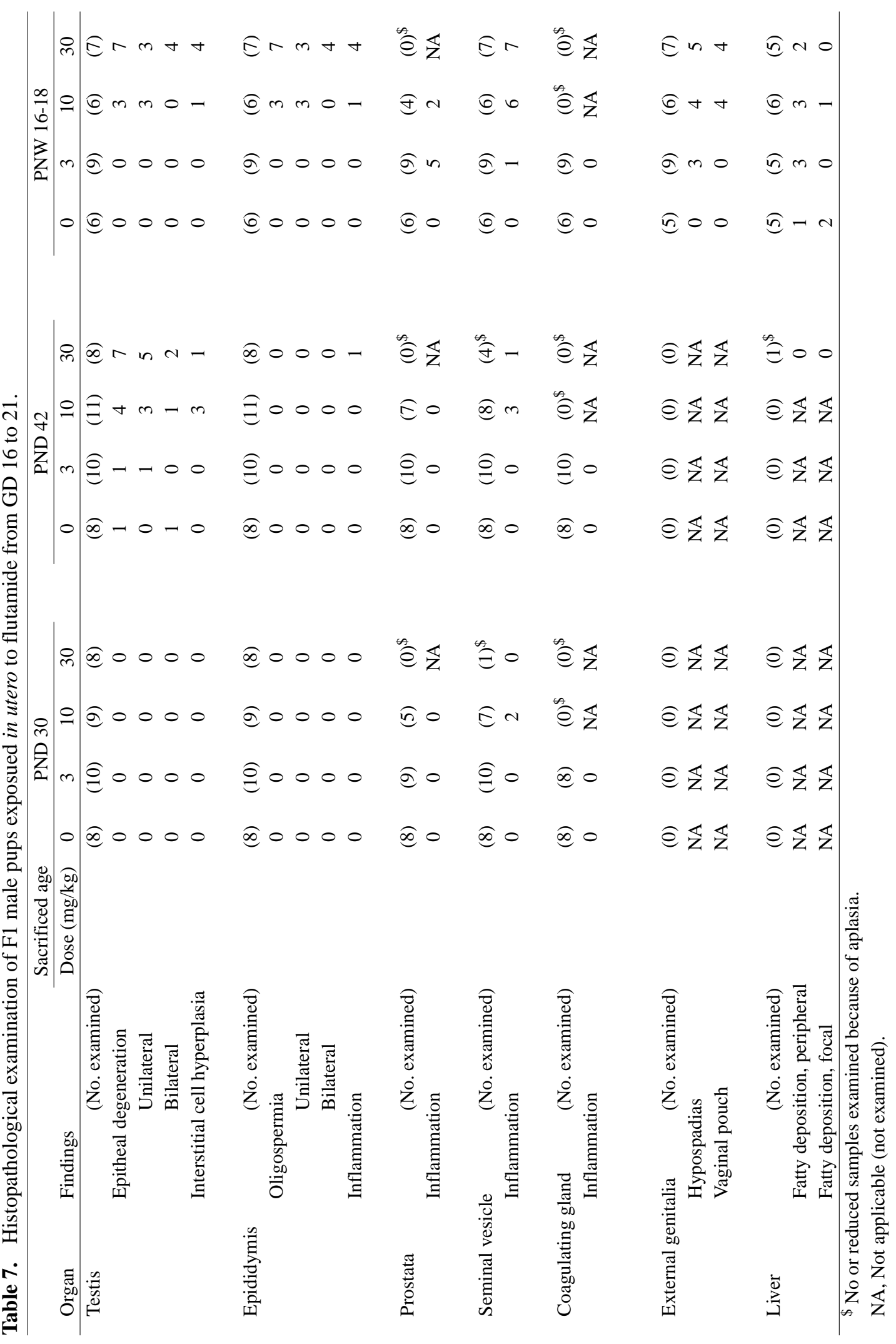

Vol. 29 No. 5 


\section{K. GOTO et al.}
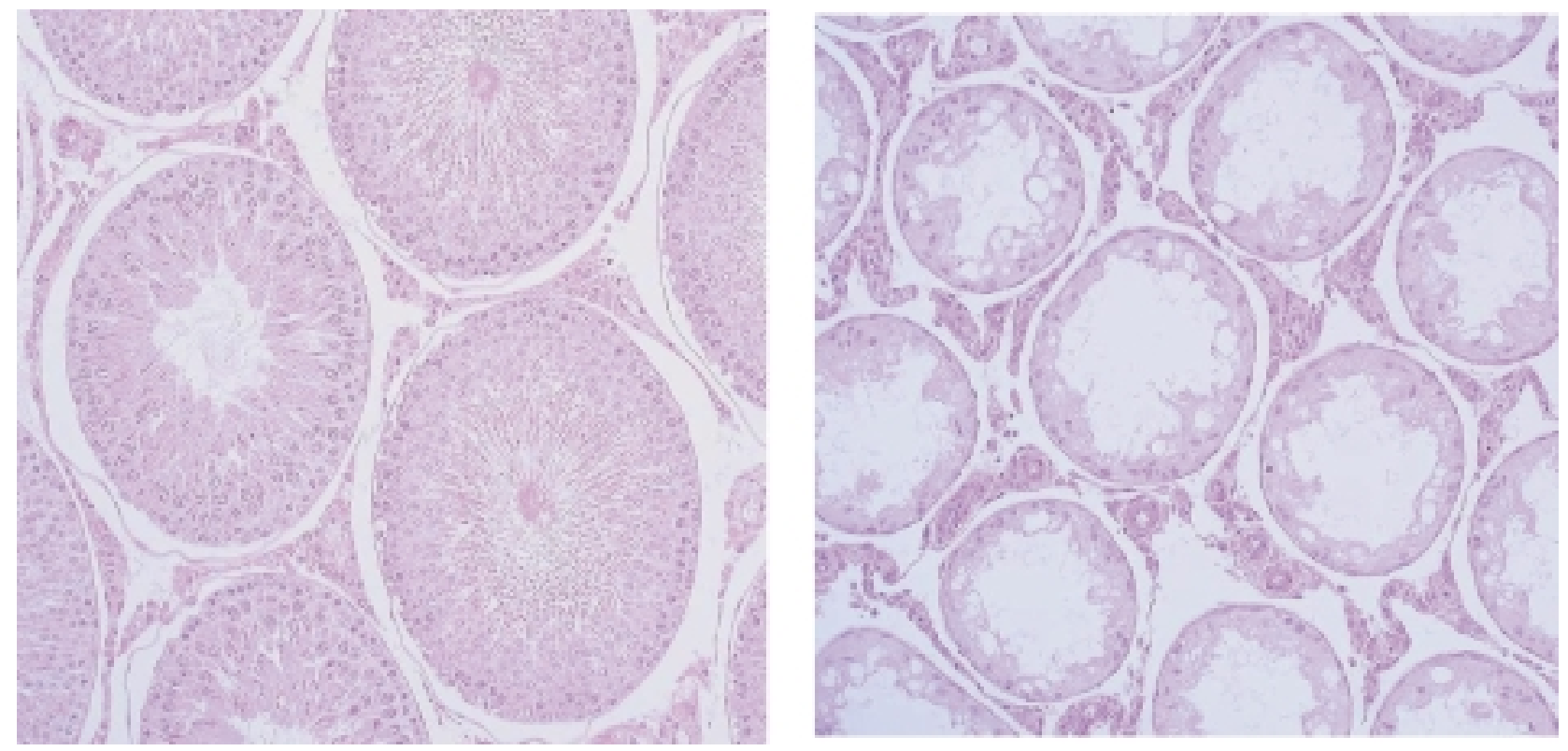

Photo 1. Testes from F1 male rats (18 week-old) exposed to flutamide at $30 \mathrm{mg} / \mathrm{kg} /$ day during late pregnancy. $(\times 188)$ Left: control. Right: $30 \mathrm{mg} / \mathrm{kg}$ group showing degeneration of seminiferous tubule and persistent sertoli cells (sertoli cellonly syndrome).
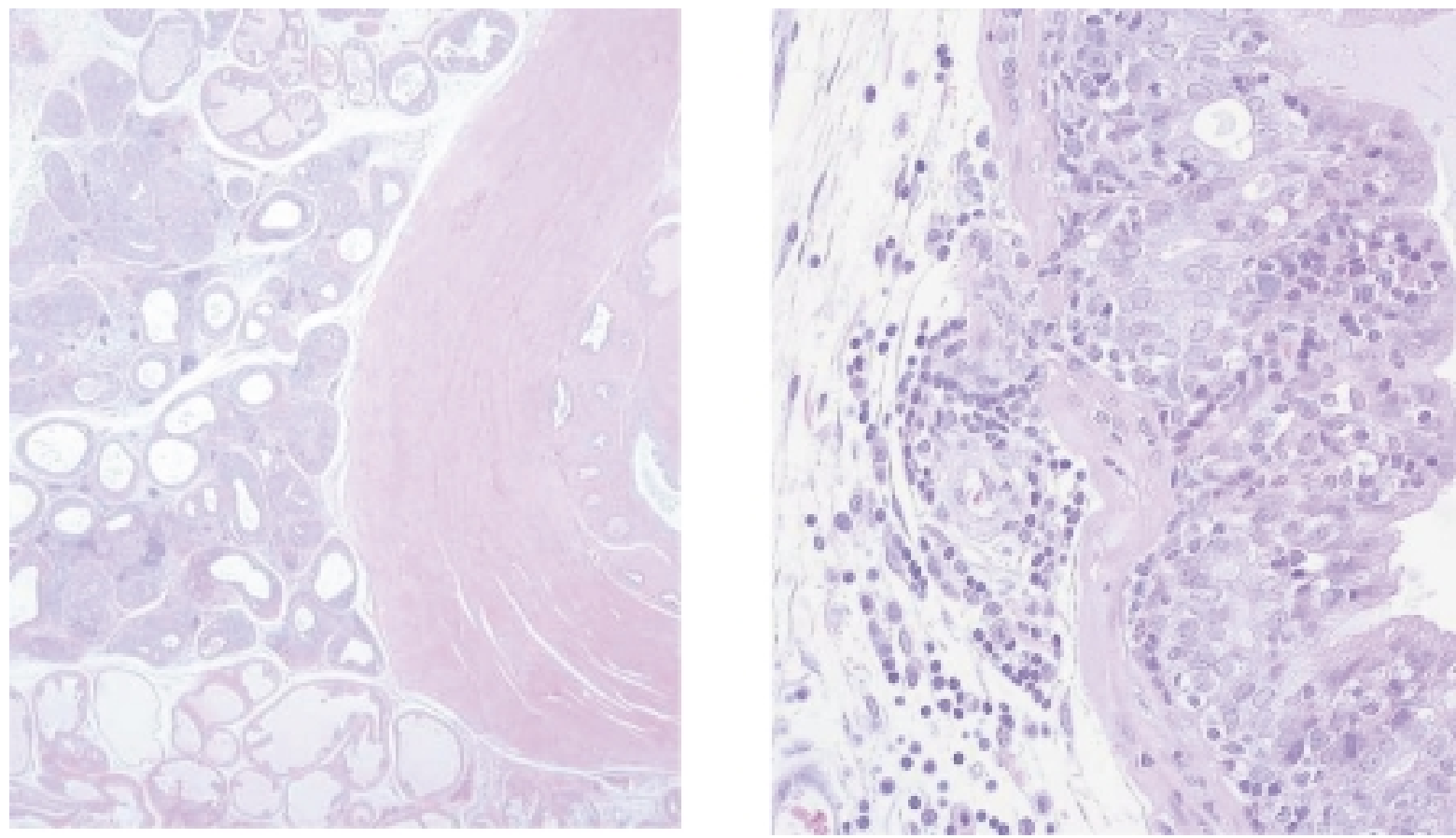

Photo 2. Prostate from F1 male rat (18-week-old) exposed to flutamide at $30 \mathrm{mg} / \mathrm{kg} /$ day during late pregnancy. Left: inflammation of lateral lobe (upper area) and dorsal lobe (lower area) of prostate. $(\times 20)$

Right: (High magnification of the lateral lobe) infiltrated lymphocytes are seen. $(\times 400)$ 
Sex maturation and behavior of offspring exposed to flutamide.

external abnormalities in females or males and no change in AGD. According to Yallampalli et al. (1993), in an in vitro study using mouse embryo cells, an exposure to flutamide affected embryonic development, and this effect was inhibited by testosterone, but not by estradiol. Flutamide has been shown to exert antiandrogen effects on early embryos before implantation. Some studies have reported that treatment of rats with flutamide during pre-implantation (GD 4-6) caused a delayed implantation (Chandrasekhar et al., 1990; Chandrasekhar, 1991), but the present study found no evidence of such change. However, administration of the same doses during fetal organogenesis (GD 6-17) clearly decreased AGD in male fetuses at doses $\geq 3 \mathrm{mg} / \mathrm{kg} /$ day. This difference can be explained as follows. Androgen receptors do not begin to increase until a fetal age of about 14 days (Price and Ortiz, 1965; Bentvelsen et al., 1995). In the pre- implantation embryo, androgen receptor protein expression and sex-related development have not yet started. The antiandrogen action of flutamide therefore has no effect at this stage. However, epigenetic modifications such as DNA imprinting and methylation occur immediately after fertilization. If exposure to a chemical substance during pre-implantation alters normal DNA methylation patterns in the embryo, this may affect normal function (Reik and Dean, 2001). In our study, treatment with flutamide during pre-implantation exerted no effects on the number of implantations or embryo/fetal survivals. These findings suggest that flutamide at subcutaneous doses of $30 \mathrm{mg} / \mathrm{kg} / \mathrm{day}$ has no toxic effects on the early embryo.

Subcutaneous administration of flutamide at doses of $\geq 3 \mathrm{mg} / \mathrm{kg} /$ day during fetal organogenesis (GD 6-17) and late pregnancy (GD 16-21) clearly decreased AGD in male pups. Several other research-

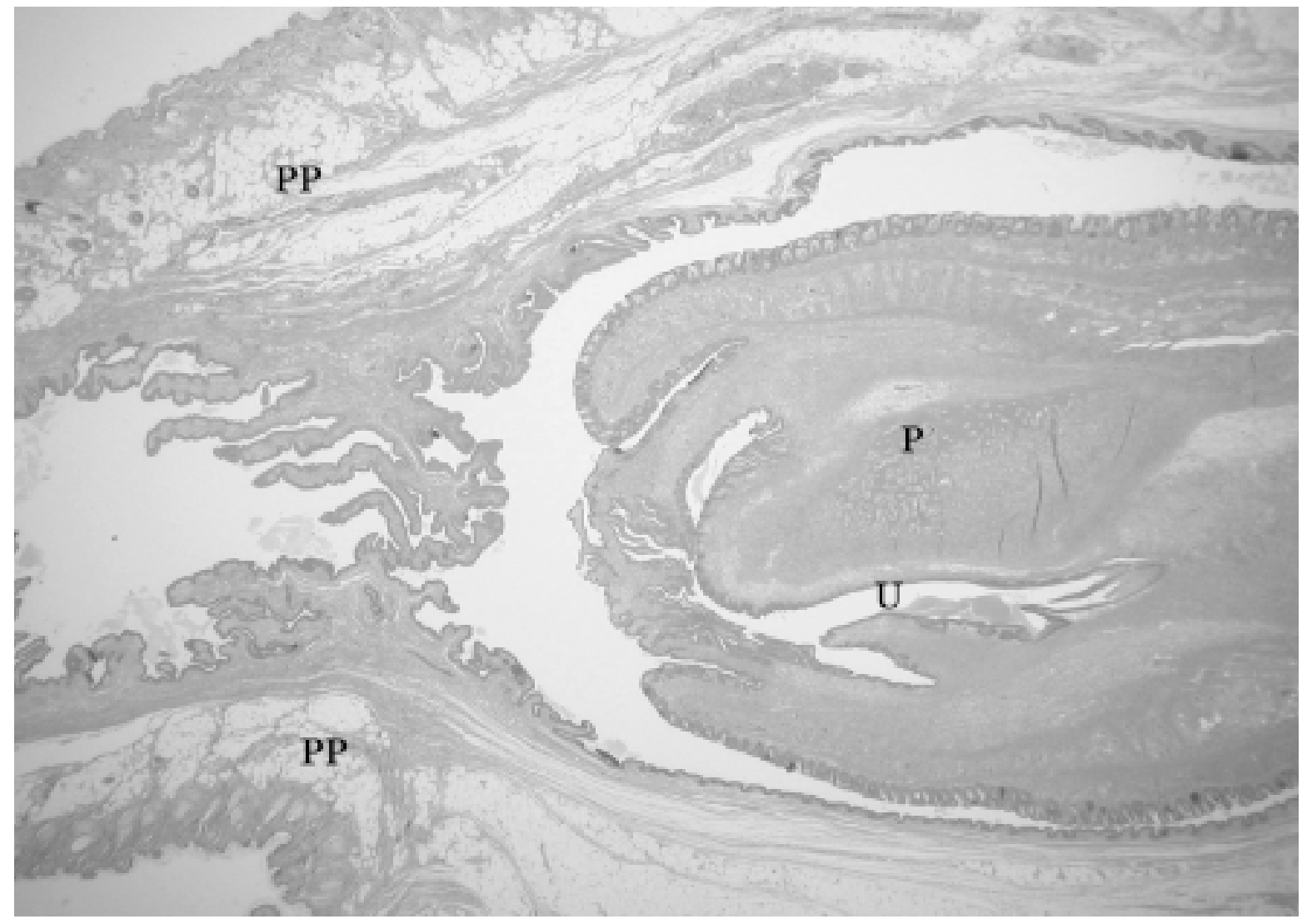

Photo 3. Sagittal section of penis(P) and prepuce $(\mathrm{PP})$ in the control (18-week-old F1 rat). $(\times 20)$

Normal penis and prepuce are shown.

P : penis, U: Urethra, PP : Prepuce. 


\section{K. GOTO et al.}

ers have reported similar effects of flutamide (Miyata et al., 2002; McIntyre et al., 2001) and other antiandrogen agents (Shono et al., 2004; Barlow et al., 2004; Ema et al., 2003; Bowman et al., 2003) on sexual maturity in males. Miyata et al. (2002) reported that oral administration of flutamide at $\geq 2.5 \mathrm{mg} / \mathrm{kg} /$ day from GD 14 to PND 3 decreased AGD, and McIntyre et al. (2001) observed similar findings at oral doses of $6.25 \mathrm{mg} / \mathrm{kg} / \mathrm{day}$. In our study too, decreased AGD was induced from low dose while abnormalities of the internal genitalia (e.g., prostate hypoplasia) occurred at $10 \mathrm{mg} / \mathrm{kg}$ and higher. Thus, AGD appears to offer one of the most sensitive markers for detecting abnormal sexual differentiation.

Similar to the results seen in the treatments dur- ing early pregnancy and organogenesis periods, subcutaneous administration of flutamide at doses up to 30 $\mathrm{mg} / \mathrm{kg}$ /day during late pregnancy (GD 16-21) had no significant effect on body weight gain of dams, nor were toxic signs observed. Reproductive function in the treated dams was not affected by treatment. Thus, slightly but significantly reduced bodyweight of the male offspring at a dose of $30 \mathrm{mg} / \mathrm{kg}$ at weaning on PND 21 might not be attributable to maternal ill health caused by treatment. It is considered to reflect a direct effect of flutamide on fetuses because it can be readily permeable through placenta (no data shown). Other postnatal developmental characteristics such as physical traits including eruption of incisors and eyelid opening were not affected in those males at a dose of

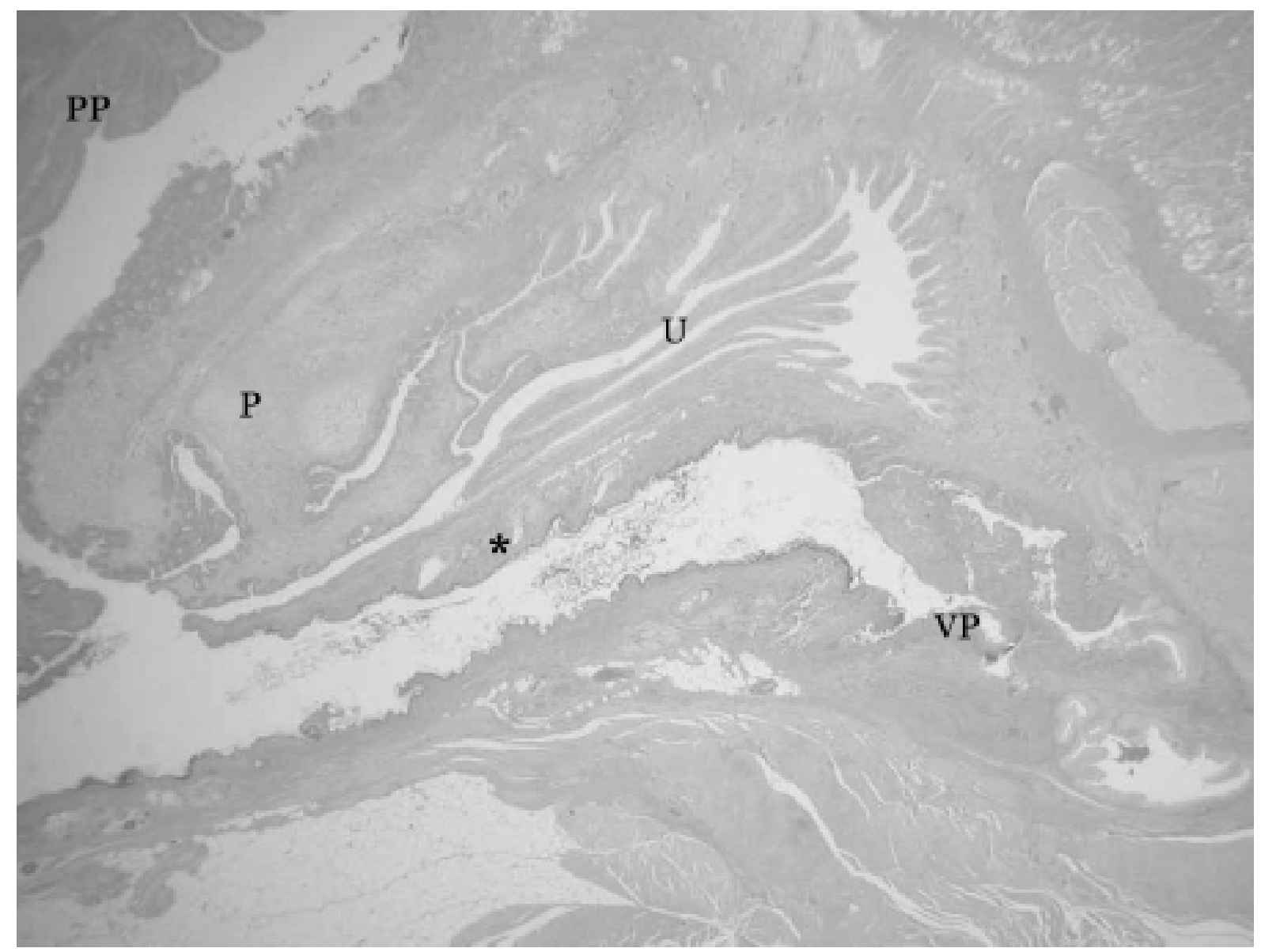

Photo 4. Sagittal section of external genitalia in the $30 \mathrm{mg} / \mathrm{kg}$ group (18 week-old $\mathrm{F} 1 \mathrm{rat}) .(\times 20)$

Urethra $(\mathrm{U})$ is open underneath the penis (P) (Hypospadias) and blind vaginal pouch is formed. Prepuce of ventral side of penis is hypoplastic and ventral layer of glans penis has not formed.

P : Penis, U : Urethra, VP : Vaginal pouch, PP : Prepuce, * : Hypoplastic prepuce. 
Sex maturation and behavior of offspring exposed to flutamide.

$30 \mathrm{mg} / \mathrm{kg}$. While the physical growth represented by the bodyweight of these males seemed to catch up to the control level by PND 41, sex-related endpoints were severely affected. AGD at birth was significantly and dose-dependently shortened in each dose group compared to controls as mentioned above. Preputial separation as a parameter for sex maturation was especially delayed by an average of 3.65 days at a dose of $30 \mathrm{mg} / \mathrm{kg}$, although the delay was 0.68 days at doses of 3 and $10 \mathrm{mg} / \mathrm{kg}$. Thus, the changes in sexual characteristics shown above would occur independently from physical growth in general. Developmental fate of the sex-related characteristics might be altered during their fetal period by maternal treatment with flutamide.

The following are also examples of change in commitment of the developmental fate of sex-related characteristics by prenatal flutamide treatment (GD1621). Cryptorchidism and absence of the prostate gland and seminal vesicles were found at doses $\geq 10 \mathrm{mg} / \mathrm{kg}$, and testicular hypoplasia at dose of $30 \mathrm{mg} / \mathrm{kg}$. Hypospadias was detected in all dose groups and vaginal pouches clearly increased at doses $\geq 10 \mathrm{mg} / \mathrm{kg}$. In relation to the pathogenesis of cryptorchidism, it has been shown that differentiation of the genitoinguinal ligament to the gubernaculum testis and further contraction leading to testicular descent is under the influence of testosterone (Goh et al., 1994). In the present study, cryptorchidism was generally unilateral, with few instances of bilateral cryptorchidism. No predilection for laterality of the abnormality was noted, but the reason for unilateral cryptorchidism occurred despite systemic exposure to flutamide is unclear. A similar result was reported by van der Schoot (1992). Histological examination of the testes on PND 30 showed no abnormalities, but on PND 42 and later on, epithelial degeneration of the seminiferous tubules was observed at doses $\geq 10 \mathrm{mg} / \mathrm{kg}$. Undescended testes were smaller in weight than descended testes, and the histological degeneration in the testis was attributed to abdominal cryptorchidism. In a study of flutamide-induced cryptorchidism, Kassim et al. (1997) found differences in degree of abnormalities of spermatogenesis, depending on the intra-abdominal position of the testes, which support our findings of testicular degeneration being a secondary change due to abdominal cryptorchidism. Association of the testicular hypospermatogenesis and lower number of sperm in the lumen of the epididymal ductules was evidenced by histological findings at the final necropsy (PNW 16-18). In addition, animals at a dose of $30 \mathrm{mg} / \mathrm{kg}$ showed evidence of inflammation (spermatic granuloma). At doses of $\geq 10 \mathrm{mg} / \mathrm{kg}$, some animals also displayed absence of the prostate, seminal vesicles, and coagulating glands, so that ductules in accessory sex organs might be hypoplastic as an obstacle to passing seminal fluid, and thus causing some inflammatory reactions. Histological examination identified inflammation of the hypoplastic prostate and seminal vesicles, and incidence of inflammation tended to increase with number of days after birth. Inflammation of the prostate was not observed in any dose groups on early PNDs such as 30 and 42, and a correlation with hypospadias was also noted. The prostatic hypoplasia and inflammation caused by prenatal exposure to antiandrogens have been reported (Prinsac et al., 2001; You et al., 1999; Stoker et al., 1999). However, another possibility of referring to urinary tract infection due to hypospadias still remains. Histopathological examination of the external genitalia in the affected males revealed hypoplastic prepuce of the ventral side of the penis and dislocation of urethra in the glans penis, resulting in a loss of the ventral epithelial layer of the penis. Yoshimura et al. (2004) showed that the urethral dislocation was due to aplasia of the ventral half of the glans penis.

The present study also showed mysterious relevance or some discrepancies between hormonal levels and mating behavior of the male offspring maternally treated with flutamide during late pregnancy. First, serum testosterone levels were comparable in males of all dose groups and in controls. Nevertheless, male sexual behavior determined by numbers and latent periods for mounting, intromission and ejaculation were significantly and dose-dependently affected. Number and frequency of mounts with intromission were markedly decreased with doses $\geq 3 \mathrm{mg} / \mathrm{kg}$. No ejaculatory behavior was observed at dose of $\geq 10 \mathrm{mg} /$ $\mathrm{kg}$, and in addition, non-intromittive mounting was observed at a dose of $30 \mathrm{mg} / \mathrm{kg}$. These changes in sexual behavior were closely correlated with abnormalities of the external genitalia. No animals with hypospadias displayed mounting with ejaculation. At the dose of $30 \mathrm{mg} / \mathrm{kg}$, structural abnormalities of the penis were prominent, as mentioned previously, and this malformed penis might lead to failure of intromission and ejaculation. No constant patterns in times of the latent periods of each type of sexual behavior were apparent. Thus we recognized these phenomena as some form of demasculinization event that might occur in these males, although representative feminization, as evidenced by lordosis, was not observed. The effect of sex hormones on sex behaviors of the intact or castrated male rats has been established. Gladue and 
Clemens (1980) induced sexual behavior in castrated rats with testosterone and showed that mounting, intromission, and ejaculation were testosterone-dependent. Treatment with flutamide inhibited these sexual behaviors. These figures on flutamide effect do not explain our results, because at adulthood, flutamide or its active metabolite, 2-hydroxyflutamide, would no longer exist in the males prenatally exposed to flutamide, given the short terminal half-lives of these compounds (Xu et al., 1998). Casto et al. (2003) also reported similar results. Reduced non-intromittive mounting without sex hormonal change observed in all treatment groups (Fig. 3; no statistical significance, but clearly dose-dependent) might be due to incomplete sexual differentiation of the central nervous system resulting from the prenatal exposure to antiandrogen flutamide. Flutamide administered during late pregnancy also reduces the size of the sexually dimorphic nucleus of the preoptic area (SDN-POA) in the male offspring (Lund et al., 2000). The SDN-POA is generally larger in males than females in rats (Gorski et al., 1980), and its volume has been correlated with male sexual behavior (Rhees et al., 1999). We presented not only some new phenomena in relevance to demasculinization, but also the fact that these events causing impairment of the male sexual behaviors would have been established during the late pregnancy period as a change in commitment of the developmental fate of sex-related organs and brain.

Thus, exposure of fetuses to flutamide during late pregnancy produced some disturbances of male sexual maturation in adulthood, including abnormalities of internal and external genitalia and sexual behavior, in spite of normal circulated levels of sex hormones. Flutamide as antiandrogen exposure during early development may produce permanent imprints on sex organs and possibly the brain which lead to reduced growth, differentiation defects of the epithelial cells, altered secretary function and reduced responsiveness to androgens in adulthood.

Reproductive function with ability to impregnate females, as determined by conception rate (number of pregnant females / number of females mated), was $80 \%(4 / 5)$ at dose of $3 \mathrm{mg} / \mathrm{kg}$, and $100 \%(8 / 8)$ in the control group. Animals with normal copulation and successful ejaculation were considered fertile. Sperm tests were not performed, but the above results indicate no abnormalities in fertility rate with sperm from animals demonstrating normal copulatory behavior. There seemed to be a certain threshold for demasculinization effect of flutamide when administered to the maternal rat during late pregnancy.

The present results suggest that a normal androgenic environment is essential for the sexual maturation of males, and that when fetuses are exposed to an antiandrogen flutamide during late pregnancy, irreversible abnormalities in sex-related organs and behavior would be observed in male offspring after birth. Further studies are necessary to clarify why normal sexual behavior was not seen in the male offspring thus treated with flutamide in spite of normal testosterone level. This may mean a search for the actual target of the flutamide in male fetus at late pregnancy.

\section{REFERENCES}

Balk, P. (2002): Androgen receptor as a target in androgen-independent prostate cancer. Urology. 60 (Suppl 1), 132-138.

Barlow, N.J., McIntype, B.S. and Foster, P.M. (2004): Male reproductive tract lesions at 6,12 and 18 months of age following in utero exposure to di(n-butyl) phthalate. Toxicol. Pathol., 32, 7990.

Bartlett, M.S. (1937): Properties of sufficiency and statistical tests. Proc. Roy. Soc., A160, 268-282.

Bentvelsen, F.M., Brinkmann, A.O., van der Schoot, P., van der Linden, J.E.T.M., van der Kwast, Th.H., Boersma, W.J.A., Schroder, F.H. and Nijman, J.M. (1995): Developmental pattern and regulation by androgens of androgen receptor expression in the urogenital tract of the rat. Mol. Cell. Endocrinol.. 113, 245-253.

Bowman, C.J., Barlow, N.J., Turner, K.J., Wallance, D.G.. and Foster, P.M. (2003): Effects of in utero exposure to finasteride on androgendependent reproductive development in the male rat. Toxicol. Sci., 74, 393-406.

Brand, T. and Slob, A.K., (1991): Perinatal flutamide and mounting and loadosis behavior in adult female Wistar and Sprague-Dawley rats. Behav. Brain Res. 44, 43-51.

Cagen, S.Z., Waechter, J.M. Jr., Dimond, S.S., Breslin, W.J., Butala,J.H., Jekat, F.W., Joiner, R.L., Shiotsuka, R.N., Veenstra, G.E. and Harris, L.R. (1999): Normal reproductive organ development in Wistar rats exposed to bisphenol $\mathrm{A}$ in the drinking water. Regul. Toxicol. Pharmacol., 30 (Pt 1), 130-139.

Casto, J.M., Ward, O.B. and Bartke, A. (2003): Play, copulation, anatomy, and testosterone in gonadally intact male rats prenatally exposed to fluta- 
Sex maturation and behavior of offspring exposed to flutamide.

mide. Physiol. Behav., 79, 633-641.

Chandrasekhar, Y., Armstrong, D.T. and Kennedy, T.G.. (1990): Implantation delay and anti-deciduogenic activity in the rat by the anti-androgen, hydroxyflutamide. Biol. Reprod., 42, 120-125.

Chandrasekhar, Y. (1991): Effects of hydroxyflutamide on female reproductive function. Adv Contracept Deliv Syst., 7, 157-166.

Clark, R.L., Antonello, J.M., Grossman, S.J., Wise, L.D., Anderson, C.A. Bagdon, W.J., Prahalada, S., MacDonald, J.S. and Robertson, R.T. (1990): Teratology, 42, 91-100.

Clark, R.L., Anderson, C.A., Prahalada, S., Robertson, R.T., Lochry, E.A., Leonard, Y.M., Stevens, J.L. and Hoberman, A.M. (1993): Toxicol. Appl. Pharmacol., 119, 34-40.

Clemens, L.G., Gladue, B.A. and Coniglo, L.P. (1978): Prenatal endogenous androgenic influences on masculine sexual behavior and genital morphology in male and female rats. Horm. Behav., 10, 40-53.

Dunnett, C.W. (1955): A multiple comparison for compraring several treatments with a control. J. Am. Statist. Assoc., 50, 1096-1121.

Ema, M., Miyawaki, E., Hirose, A. and Kamata, E. (2003): Decreased anogenital distance and increased incidence of undescended testes in fetuses of rats given monobenzyl phthalate, a major metabolite of butyl benzyl phthalate. Reprod. Toxicol., 17, 407-412.

Gladue, B.A. and Clemens, L.G.. (1978): Androgenic influences on feminine sexual behavior in male and female rats: Defeminization blocked by prenatal androgen treatment. Endocrinology, 103, 1702-1709.

Gladue, B.A. and Clemens, L.G. (1980): Flutamide inhibits testosterone-induced masculine sexual behavior in male and female rats. Endocrinology, 106, 1917-1922.

Gladue, B.A. and Clemens, L.G.. (1982): Development of feminine sexual behavior in the rat: Androgenic and temporal influences., Physiol. Behav., 29, 263-267.

Goh, D.W., Middlesworth, W., Farmer, P.J. and Hutson, J.M. (1994): Prenatal androgen blockade with Flutamide inhibits masculinization of the genitofemoral nerve and testicular descent. J. Pediatr. Surg., 29, 836-838.

Gorski, R.A., Harlan, R.E., Jacobson, C.D., Shryne, J.E. and Southam, A.M. (1980): Evidence for the existence of a sexually dimorphic nucleus in the preoptic area of the rat. J. Comp. Neurol., 193, 529-539.

Gray, L.E.Jr., Ostby, J. and Kelce, W.R. (1994): Developmental effects of an environmental antiandrogen: The fungicide vinclozolin alters sex differentiation of the male rat. Toxicol. Appl. Pharmacol., 129, 46-52.

Hokao, R, Saito, T. and Takahashi, K. (1993): Comparison of sexual behavior patterns in small laboratory animals. Exp. Anim., 42, 451-455.

Hokao, R. and Saito, T. (1994): Depression of male sexual function with aging-its cause and improvement-. Jap. J. Perin. Care., 13, 58-65.

Imperato-McGinley, J., Sanchez, R.S., Spencer, J.R., Yee, B. and Vaughan, E.D. (1992): Comparison of the effects of the 5 alpha-reductase inhibitor finesteride and the antiandrogen Flutamide on prostate and genital differentiation: Doseresponse studies. Endocrinology, 131, 11491156.

Kassim, N.M., McDonald, S.W., Reid, O., Bennett, N.K., Gilmore, D.P. and Payne, A.P. (1997): The effects of pre- nad postnatal exposure to the nonsteroidal antiandrogen Flutamide on testis descent and morphology in the Albino Swiss rat. J. Anatomy, 190, 577-588.

Lund, T.D., Salyer, D.L., Fleming, D. E. and Lephart, E. D. (2000): Pre- and postnatal testosterone and Flutamide effects on sexually dimorphic nuclei of the rat hypothalamus. Dev. Brain Res., 120, 261-266.

McIntyre, B.S., Barlow, N.J. and Foster, P.M. (2001): Androgen-mediated development in male rat offspring exposed to Flutamide in utero: Permanence and correlation of early postnatal changes in anogenital distance and nipple retention with malformations in androgen-dependent tissues. Toxicol. Sci., 62, 236-249.

Miyata, K., Yabushita, S., Sukata, T., Sano, M., Yoshino, H., Nakanishi, T., Okuda, Y. and Matsuo, M. (2002): Effects of perinatal exposure to flutamide on hormones and androgendependent organs in F1 male rats. J. Toxicol. Sci., 27, 19-33.

Mylchreest, E., Cattley, R.C and Foster, P.M.D. (1998): Male reproductive tract malformations in rats following gestational and lactational exposure to di(n-butyl) phthalate: An antiandrogenic mechanism? Toxicol. Sci., 43, 47-60.

Ostby, J., Kelce, W.R., Lambright, C., Wolf, C.J., Mann, P. and Gray, L.E.Jr. (1999): The fungi- 
cide procymidone alters sexual differentiation in the male rat by acting as an androgen-receptor antagonist in vivo and in vitro. Toxicol. Ind. Health, 15, 80-93.

Price, D. and Oritiz, E. (1965): In Organogenesis (Ursprung, R.L., de Haan, H., eds.), pp. 629652, Holt, Rinehart and Wiston, New York.

Prinsac, G.S., Brirch, L., Habermann, H., Chang, W.Y., Tebeau, C. and Putz, O. (2001): Influence of neonatal estrogens on rat prostate development. Reprod. Fertil. Dev., 13, 241-252.

Reik, W. and Dean, W. (2001): DNA methylation and mammalian epigenetics. Electrophoresis, 22, 2838-2843.

Rhees, R.W., Al-Saleh, H.N., Kinghorn, E.W., Fleming, D.E. and Lephart, E.D. (1999): Relationship between sexual behavior and sexually dimorphic structures in the anterior hypothalamus in control and prenatally stressed male rats. Brain Res. Bull., 50, 193-199.

Sato, M., Shimada, M. and Sato, Y. (2001): The effects of prenatal exposure to ethinyl estradiol and bisphenol-A on the developing brain, reproductive organ and behavior of mouse. Cong. Anomal., 41, 187-193.

Shono, T., Suita, S., Kai, H. and Yamaguchi, Y. (2004): The effect of a prenatal androgen disruptor, vinclozolin, on gubernacular migration and testicular denscent in rats. J. Pediatr Surg., 39, 213-216.

Sodersten, P., Gray, G., Damassa, D.A., Smith, E.R. and Davidson, J.M. (1975): Effects of a nonsteroidal antiandrogen on sexual behavior and pituitary-gonadal function in the male rat. Endocrinology, 97, 1468-1475.

Steel, R.G.D. (1959): A multiple comparison rank sum test: Treatments versus control. Biometrics, 15, 560-572.

Stoker, T.E., Robinette, C.L. and Cooper, R.L. (1999): Perinatal exposure to estrogenic compounds and the subsequent effects on the prostate of the adult rat: Evaluation of inflammation in the ventral and lateral lobes. Reprod. Toxicol., 13, 463472.

Vagell, M.E. and McGinnis, M.Y. (1998): The role of gonadal steroid receptor activation in the restoration of sociosexual behavior in adult male rats.
Horm. Behav., 33, 163-179.

van der Schoot, P. (1992): Disturbed testicular descent in the rat after prenatal exposure to the antiandrogen flutamide. J Reprod. Fertil., 96, 483496.

Vega Matuszczyk, J.V. and Larsson, K. (1995): Sexual preference and feminine and masculine sexual behavior of male rats prenatally exposed to antiandrogen or antiestrogen. Horm. Behav., 29, 191-206.

Wise, L.D., Minsker, D.H., Cukierski, M.A., Clark, R.L., Prahalada, S., Antonello, J.M., MacDonald, J.S. and Robertson, R.T. (1991): Reversible decreases of fertility in male Sprague-Dawley rats treated orally with finasteride, a 5 alpha-reductase inhibitor. Reprod. Toxicol., 5, 337-346.

Xu. C.J. and Li, D. (1998) : Pharmacokinetics of flutamide and its metabolite 2-hydroxyflutamide in normal and hepatic injury rats. Zhongguo Yao Li Xue Bao Jan, 19, 39-43.

Yallampalli, C., Osuamkpe, C. and Nagamani, M. (1993): Influence of the anti-androgen hydroxyflutamide on in vitro development of mouse embryos. J Reprod. Fertil., 99, 467-470.

Yoshimura, S., Yamaguchi, H., Konno, K., Ohsawa, N., Noguchi, S. and Chisaka, A. (2004): Hypospadias and incomplete preputial separation in male rats induced by prenatal exposure to an anti-androgen, flutamide. J. Toxicol. Pathol., 17, 113-118.

You, L., Casanova, M., Archbeque-Engle, S., Sar, M., Fan, L. and Heck, H.d'A. (1998): Impaired male sexual development in perinatal Sprague-Dawley and Long-Evans hooded rats exposed in utero and lactationally to $p, p$ '-DDE. Toxicol. Sci., 45, 162-173.

You, L., Brenneman, K.A. and Heck, H. (1999): In utero exposure to antiandrogens alters the responsiveness of the prostate to $p, p^{\prime}$-DDE in adult rats and may induce prostatic inflammation. Toxicol. Appl. Phamacol., 161, 258-266.

Zimmerberg, B. and Farley, M.J. (1993): Sex differences in anxiety behavior in rats: Role of gonadal hormones. Physiol. Behav., 54, 11191124. 